\title{
La parlamentarización del sistema político de la Unión Europea: sus consecuencias para la legitimidad*
}

\author{
The Parliamentarization of the EU's Political System:
} its Impact on Legitimacy

\author{
Alberto Priego \\ Universidad P. Comillas \\ Gracia Abad \\ Universidad Antonio de Nebrija
}

\begin{abstract}
Sumario: I. Introducción. - II. El modelo de la Unión Europea. Debates y contradicciones. 1. El Modelo de Integración Funcional/Comunitario frente al Constitucional. 2. El Método de la Conferencia Intergubernamental Vs la Reforma Constitucional.-III. Los Sistemas Políticos.-IV. El Sistema Político de la UE.-V. Conclusiones.-Bibliografía.
\end{abstract}

Resumen: La Unión Europea es un sistema político rígido establecido con la creación de la CECA. La reforma del mismo es difícil ya que coexisten dos sensibilidades: la funcional/comunitaria y la constitucional. Sin embargo, esa rigidez que limita la reforma entra en conflicto con la necesidad de la Unión Europea de reformar sus instituciones para adaptarse a las nuevas realidades, siendo la inclusión de elementos propios de los sistemas políticos clásicos - tanto presidencialistas como parlamentarios - la única vía posible de reforma. Hasta el momento han sido más los elementos de carácter parlamentario introducidos que los presidencialistas, algo que dado que en Europa los sistemas parlamentarios son más comunes y, por ello percibidos como más legítimos por sus ciudadanos, puede afectar favorablemente a la legitimidad de la UE.

Palabras clave: Parlamentarismo, Presidencialismo, Unión Europea, Legitimidad.

Abstract: The European Union is a rigid political system established with the creation of the ECSC. Its reform is difficult because two different sensibilities coexist: the Functional/Communitarian and Constitutional one. However, the EU needs to reform its institutions in order to adapt them to the new international order, the only option for reform being the addition of elements borrowed from the classical

* Recibido el 16 de diciembre de 2014, aceptado el 26 de enero de 2015. 
political systems, both parliamentary and presidential. Until now, most of the elements adopted have been parliamentary in nature. This could benefit EU legitimacy, as parliamentary systems are more common in Europe and are, therefore, perceived as more legitimate by the Europeans.

Keywords: Parliamentarism, Presidentialism, EU, Legitimacy.

\section{Introducción}

La Unión Europea tiene una estructura institucional rígida y difícilmente modificable que quedó establecida con la creación de la CECA. La explicación a esta particularidad es la coexistencia de dos sensibilidades o visiones sobre cómo debería llevarse a cabo el proceso de construcción europea: La primera, que podríamos denominar intergubernamental o unionista, busca fomentar la cooperación entre los Estados pero no ceder soberanía. La segunda, la federal o constitucional, tiene por objetivo alcanzar una mayor integración entre los miembros con un ideal que sería la creación de un Estado de carácter federal.

Debido a esta particularidad, la UE tiene limitada su capacidad para reformar sus instituciones. Por ello, la única posibilidad para alterar la estructura institucional es añadir elementos propios de los sistemas políticos clásicos (parlamentario, semipresidencial o presidencial) sin modificar sustancialmente la arquitectura creada desde que, en 1952, entrara en vigor el tratado de la CECA (Comunidad Europea del Carbón y del Acero). Como ejemplo de esta dinámica podemos citar la creación de un Presidente para el Consejo Europeo, la posibilidad de aprobar una moción de censura contra la Comisión o las, cada vez más importantes, funciones presupuestarias y legislativas del Parlamento. Entre estas medidas destacan sobre las demás aquellas propias de los sistemas parlamentarios, algo que, más allá de la reforma del sistema, puede contribuir a reducir el tan manido déficit democrático de la Unión Europea. En efecto, existe la percepción generalizada de que en la medida que el sistema sea más parlamentario, la UE será más democrática, ya que el Parlamento es la única institución de la Unión elegida directamente por ciudadanos, lo que al propio tiempo hará que la Unión Europea sea también más legítima y sostenible. Por el contrario, en la medida en que se incorporen elementos propios de los sistemas presidenciales, la UE será vista con peores ojos por parte de los ciudadanos, pues tales elementos previsiblemente tendrían su origen en las preferencias del Consejo, esto es, de los estados.

Este artículo se va a organizar de la siguiente forma. En un primer momento analizaremos las visiones contrapuestas y las contradicciones del proceso de integración que han condicionado el modelo institucional de la 
UE; a continuación veremos las características básicas los sistemas políticos clásicos; finalmente abordaremos el análisis de las características actuales del modelo político e institucional de la UE, identificando aquellos aspectos que pueden favorecer especialmente que la Unión sea percibida por sus ciudadanos como un modelo legítimo.

\section{El modelo de la Unión Europea. Debates y contradicciones}

La Unión Europea bien puede ser descrita como el proceso de integración más exitoso de la historia. Así, numerosos autores apuntan que se trata de una comunidad política cuasi-estatal que, no obstante, mantiene algunos elementos propios ${ }^{1}$. En este sentido, muchos son los autores, como Grajauskas ${ }^{2}$ o Caporaso $^{3}$, que han señalado que la UE puede ser considerada el primer Estado postmoderno. Por esta razón, la UE no debería ser analizada bajo el prisma estatal clásico ya que, tal y como señala Jo Shaw, la UE es una entidad que va más allá del estado (beyond the state ${ }^{4}$ ). Sin embargo, no debemos olvidar que el proyecto europeo nació como una organización internacional aunque su evolución posterior la convierta en algo difícilmente clasificable.

$\mathrm{Al}$ respecto, uno de los mayores expertos en Instituciones Internacionales, Rittberger, sostiene que las peculiaridades inherentes a la Unión Europea desde su nacimiento están en la raíz de las particulares características de su modelo institucional, unas características establecidas ya desde el origen de la UE. Así, según Rittberger ${ }^{5}$ la estructura institucional la UE, que no se habría alterado sustancialmente desde la CECA, estaría compuesta por los siguientes órganos:

a) Un ejecutivo supranacional y cuasi-legislador (Comisión) que velaría por los intereses de la UE como tal.

1 «Many of the EU's opponents and critics subscribe to the view that the nation state, not an international organization, is the natural supreme political unit» NUGENTS, N., The Government and Politics of the European Union, ed. Palgrave-MacMillan, London, 2010 ( $7^{\text {th }}$ edition) p. 1 .

2 GRAJAUSKAS, R. and KASCIUNAS, L., «Modern versus Postmodern Actor of International Relations: Explaining EU-Russia Negotiations on the New Partnership Agreement», Lithuanian Foreign Policy Review, 2009 (22)

3 CAPORASO, J., «The European Union and Forms of State: Westphalian, Regulatory or Post-Modern?» Journal of Common Market Studies, Volume 34, Issue 1, June 1996.

4 NEUNREITHER, K. and WIENER, A. (eds), European Integration after Amsterdam, ed. University Press, Oxford, Oxford, 1991, p. 290.

5 RITTBERGER, R., «Which institutions for post-war Europe? Explaining the institutional design of Europe's first community» Journal of European Public Policy 8:5 October 2001. 
b) Un legislativo con funciones de control (Parlamento) que representaría a los intereses de los ciudadanos.

c) Un Tribunal con funciones clásicas.

d) Un cuerpo intergubernamental con capacidad decisoria (Consejo) que se encargaría de que los Estados no pierdan el control del proceso.

Siguiendo a Rittberger, sobre la estructura institucional de la CECA se superpusieron los órganos de la CEE (Comunidad Económica Europea) y del Euratom. Si bien es cierto que algunos órganos, como el tribunal, fueron comunes a las tres comunidades, otros órganos como el ejecutivo (Comisión) tenían una existencia separada. El tratado de fusión de ejecutivos recondujo el proyecto europeo a la lógica institucional inicial demostrando que la tesis de la rigidez institucional de Rittberger estaba plenamente vigente. Veamos en el siguiente gráfico la estructura organizativa original de las tres comunidades:

Asamblea común (1952)

Tribunal de Justicia de las Comunidades Europeas
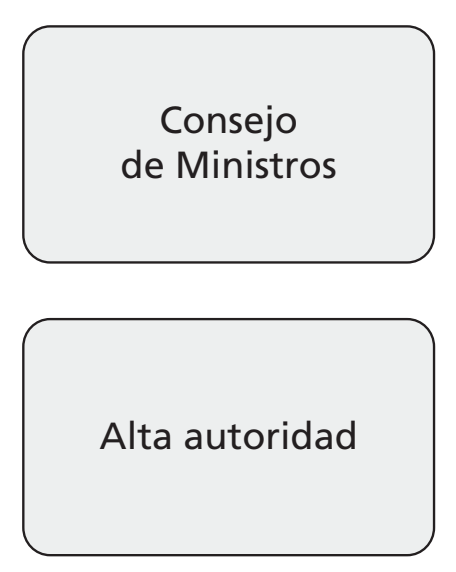

CECA 1952
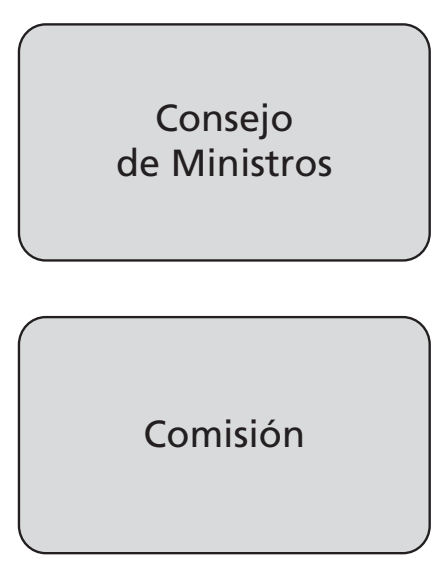

CEE 1958
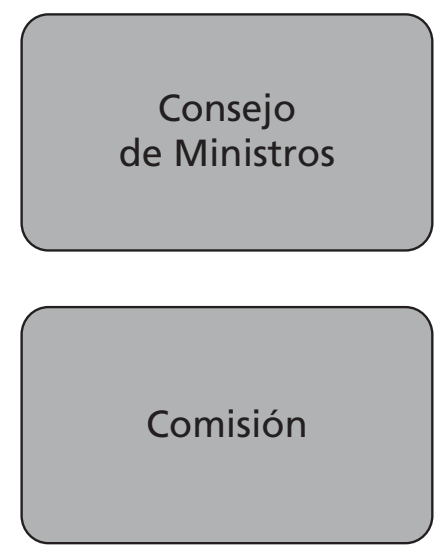

Euratom 1958

Fuente: Elaboración propia.

\section{Gráfico 1}

Estructura institucional originaria de las Comunidades Europeas 
Una vez analizada la rigidez del sistema institucional de la UE cabe preguntarse por qué no se ha modificado tal entramado institucional si el proceso de integración ha logrado importantes hitos que debían haber conllevado sustanciales cambios institucionales. La respuesta, que ya ha sido anticipada, no es otra que la existencia de dos sensibilidades contrapuestas sobre qué debe ser la UE que impiden que se dé el consenso necesario para abordar este reto:

a) Los unionistas, partidarios de la cooperación sin integración.

b) Los partidarios de una «revolución federalista ${ }^{6} »$, que buscaban la progresiva integración hasta llegar a un super Estado europeo.

Estas dos visiones han sido sistematizadas bajo diferentes terminologías. Mientras la mayor parte de los autores habla de unionistas Vs federalistas $^{7}$, otros como Andreas Staab prefieren contraponer a maximalistas y minimalistas como forma de referirse a los dos proyectos anteriormente mencionados ${ }^{8}$. Estas sensibilidades, como quiera que las llamemos, han generado dos grandes visiones que se pueden apreciar tanto en el método de trabajo del proyecto de integración, como en el modelo europeo al que se aspira y, con ello, en las posibilidades de rediseño institucional. Veamos brevemente cada uno de estos aspectos.

\section{El Modelo de Integración Funcional/Comunitario frente al Constitucional}

Un rasgo fundamental del sistema político de la Unión Europea es la adopción del llamado «Método Comunitario» frente a otros como el «Constitucional». Si bien es cierto que en los orígenes del proyecto europeo muchos fueron los que pensaron que se podría emular a los Estados Unidos, finalmente se optó por una aproximación más funcionalista que fuera integrando a los Estados de forma más progresiva. A pesar del rechazo de la opción federal, sus partidarios nunca renunciaron a su objetivo provocando que el enfrentamiento entre el «Constitutional Way» y el «Funtionalist Approach» se haya convertido en el motor de la integración

${ }^{6}$ SCOTTO, M., Las Instituciones Europeas, ed. Le Monde-Salvat, Madrid, 1996, p. 8.

${ }^{7}$ Quizás el máximo exponente de esta rama federalista fuera el proyecto de Constitución Federal Europea que Coundenhove-Kalergi presentó en 1942. Ver AHIJADO, M., Historia de la unidad europea. Desde los precedentes remotos a la ampliación al Este, ed. Ediciones Pirámide, Madrid, 2000, p. 169.

8 STAAB, A., The European Union Explained, ed. Indiana University Press, Bloomington, 2012, p. 5. 
Europea $^{9}$. En buena medida, se trata de un debate doctrinal que comenzó en 1948 con el Congreso de la Haya y cuyo último episodio lo hemos vivido en el malogrado proyecto de Constitución Europea. Hoy, con una visión mucho más amplia, podemos dibujar al menos tres momentos en los que esta tensión ha estado especialmente presente.

El primero de ellos, que bien podríamos denominar fundacional, tuvo lugar con ocasión del Congreso de la Haya de 1948, donde se marcaron las bases del proyecto europeo. Después de una guerra que devastó Europa, los mandatarios no supieron ponerse de acuerdo sobre cuál debía ser la opción de proyecto para evitar una nueva contienda de dimensiones apocalípticas. Ya entonces se podía identificar a partidarios de una «Filadelfia Europea» que buscarían formar una Asamblea Constituyente ${ }^{10}$ que elaborara una Constitución Europea que sirviera de base para los Estados Unidos de Europa. Probablemente la ausencia de un elemento histórico rupturista y violento como fue la Guerra de Independencia americana impidió que se diera tal circunstancia, haciendo que triunfaran los partidarios de la aproximación funcional frente a la constitucional. De hecho, de La Haya salió el proyecto del Consejo de Europa que encaja perfectamente con la idea unionista.

El segundo estos momentos de tensión entre funcionalistas y constitucionalistas llegó con la creación del malogrado proyecto de Comunidad Política Europea. En marzo de 1953, de la mano del que entonces era presidente de la Asamblea de la CECA, Paul-Henri Spaak, propuso la aprobación de una Constitución Europea ${ }^{11}$. Este proyecto, cuya vigencia no duró más de un año, fue vetado por Francia ${ }^{12}$ al rechazar su gobierno la creación de la Comunidad Europea de Defensa y, con ella, la Comunidad Política Europea. De nuevo, la lógica internacional y funcionalista se imponía a la constitucional manteniendo a la estructura institucional nacida de la CECA como la única posible para el proyecto europeo.

9 DEHOUSSE, R., and MAGNETTE, P., «Institutional Change in the European Union» en PETERSON, J., and SHACKLETON, M. The Institutions of the European Union, ed. Oxford University Press Oxford, 2012.

10 Eduardo Vilariño habla de «Asamblea Parlamentaria con competencias « frente a «cooperación intergubernamental exluyéndose la existencia de una Asamblea con poderes» VILARIÑO, E., La construcción de la Unión Europea, ed. Arco Libros, Madrid, 1996, p. 21.

11 «De acuerdo con el primer empuje de De Gasperi, elaboraron un proyecto de Tratado de esa Comunidad Política, que podemos considerar como el primer texto de una Constitución Política de Europa» FORNER, S. (ed.) La construcción de Europa. De las guerras civiles a la unificación. ed. Biblioteca Nueva. Insituto Alicantino de Cultura Juan Gil-Albert, Madrid, 2007, p. 85.

12 «La Asamblea Francesa rechazó la ratificación en una virulenta sesión parlamentaria el 30 de agosto de 1954» ÁLVAREZ, M. I., y ALCÓN, F., «El Parlamento Europeo. Notas sobre la Representación Política y los Sistemas Electorales» Revista de Derecho Político, n. ${ }^{\circ} 52,2001$, p. 326. 
El tercer y último momento de esta tensión llegó, ya en 2004, con el rechazo del proyecto de Constitución europea. Si bien es cierto que en este proceso se depositaron muchas esperanzas, no lo es menos que su fracaso cierra definitivamente la opción del «Constitutional way» como motor del proceso de construcción europea. El rechazo de este modelo lleva aparejado la adopción definitiva de las «Conferencias Intergubernamentales» como método para reformar y/o avanzar en el entramado institucional de la UE. Así, sin posibilidad de alterar en lo sustancial el sistema político, la única opción para modificar la estructura es la inclusión de elementos propios de los sistemas políticos clásicos sin alterar sustancialmente la estructura heredada de la CECA. Parece necesario precisar en este punto que, dadas las características de los distintos sistemas políticos a los que nos hemos referido como «clásicos» en estas páginas y la propia naturaleza de la UE, en la medida en que se busque incrementar la legitimidad del proceso se deberá tender a la parlamentarización del sistema en detrimento de otras opciones más cercanas al presidencialismo.

\section{El Método de la Conferencia Intergubernamental Vs la Reforma Constitucional}

El segundo de los elementos que nos permite apreciar las diferencias entre el «Funcionalist» y el «Constitutional Way» es el método empleado para emprender la reforma de las instituciones. En la UE cada vez que se detectan anomalías o se decide avanzar en el proyecto europeo, el método por el que se apuesta es la Conferencia Intergubernamental, dando con ello el protagonismo a los estados miembros. Con todo, este método de reforma presenta importantes carencias frente a las posibilidades que ofrece el modelo Constitucional. Veamos las diferencias básicas de estos dos métodos:

1. El modelo de Conferencia Intergubernamental adopta el método de trabajo propio de la diplomacia: la negociación internacional. Se trata de un método que busca obtener el máximo beneficio para cada uno de los Estados ${ }^{13}$ implicados en la negociación por encima, incluso, de la viabilidad del propio texto resultante. En ese mismo sentido, la negociación es una de las funciones de la diplomacia recogidas por la Convención de

13 Sobre la importancia de elementos informales en las negociaciones ver MORAVCSIK, A., «New Statecraft? Supranational Entrepreneurs and International Cooperation» International Organization, Vol. 53, N. ${ }^{\circ}$, Spring 1999, pp. 270-275 
Viena de $1961^{14}$, lo que implica que si usamos este método estaríamos hablando de acciones de Derecho Internacional Público. El profesor Carlos Closa se refiere al «estilo decisional de regateo ${ }^{15}$ » como el propio de este modelo. Por el contrario, el modelo constitucional se centra más en el debate que en la negociación, aportando elementos que tienen como principal objetivo el correcto funcionamiento del sistema, la viabilidad del texto y, por supuesto, la legitimidad del mismo.

2. El modelo de Conferencia Intergubernamental está organizado en delegaciones nacionales frente al modelo Constitucional donde las adscripciones ideológicas y/o doctrinales marcan la configuración de las partes. Siguiendo lo establecido en los puntos anteriores, en el modelo de las Conferencias Intergubernamentales las delegaciones tendrán como principal objetivo la maximización de las posiciones nacionales y no tanto la viabilidad y sostenibilidad del sistema institucional resultante. Siguiendo de nuevo a Carlos Closa, los resultados que se obtienen con este método son «sub-óptimos ${ }^{16}$ ».

3. El modelo de Conferencia Intergubernamental, tal y como hemos avanzado anteriormente, sigue las pautas del Derecho Internacional Público. Por ello, el modelo utiliza la ratificación como elemento funcional para la aprobación del texto adoptado tras la negociación ${ }^{17}$. Por el contrario, el modelo Constitucional se basa en la aprobación del texto mediante referenda o/y votaciones del mismo en la asamblea que se haya encargado de su elaboración. De hecho, si se hubiera optado por un referéndum a nivel europeo como método de ratificación de la Constitución Europea, quizás hoy estaríamos hablando de otra realidad muy distinta y seguramente el Tratado de Lisboa nunca hubiera existido. No obstante, hay autores como Weiler ${ }^{18}$ que consideran que los diferentes tratados son, de facto, textos constitucionales por lo que para ellos estas diferencias no serían significativas. Sin embargo, la opinión mayoritaria de la doctrina es

14 Art. 3.1«Las funciones de una misión diplomática consistirán principalmente en (...) c) Negociar con el gobierno del Estado receptor»

15 CLOSA, C., Sistema Político de la Unión Europea, ed. Editorial Complutense, Madrid, 1997, p. 181.

16 Ibid. 181.

17 «Article 48 TUE provides for the unanimous ratification by the member states, but of course leaves them the opportunity to decide when it might take place» PINELLI, C., «The Discourses on Post-National Governance and the Democratic Deficit Absent an EU Government» European Constitutional Law Review, September 2013.

18 WEILER, J.H.H., «Ideas and Idolatry in European Construct» en McSWEENEY, B., Moral Issues in International Affairs, ed. MacMillan, New York/Cambridge, 1998. 
diferente y por ello se habla de esta dualidad en cuanto al método de reforma que tiene su base en la existencia de estas sensibilidades que venimos señalando desde el comienzo del artículo.

Las diferencias entre visiones funcionales y constitucionales - reflejadas tanto en el modelo como en el método-, por una parte, y la opción por las primeras, por otra, impiden que se puedan hacer grandes cambios en el modelo institucional de la Unión Europea. En efecto, con dos visiones claramente irreconciliables entre los partidarios de un modelo constitucional y los que prefieren el funcional no es posible ir más allá de una redistribución de poderes entre los Estados, los ciudadanos y/o la Comisión sin alterar la esencia del sistema mismo. Esta redistribución de poderes es posible gracias a la progresiva inclusión de aspectos propios de los sistemas políticos clásicos - parlamentarios, presidenciales y semi-presidenciales - sin modificar sustancialmente el modelo fijado en la CECA hace más de 60 años, pero también sin decantarse claramente - al menos hasta el momento- por ninguno de los modelos clásicos a los que nos hemos referido.

\section{Los sistemas políticos}

Para poder apreciar qué modelos están teniendo una mayor influencia en la configuración del sistema político de la UE es necesario hacer una breve descripción de los mismos y valorar en qué medida unos u otros modelos son más atractivos para los europeos ${ }^{19}$. Los sistemas políticos pueden ser clasificados con relación a múltiples variables. Así, de acuerdo a su organización territorial hablamos de sistemas federales o unitarios. En cambio, si nos fijamos en su base electoral diferenciaríamos entre mayoritarios y proporcionales. Para nuestro trabajo la variable más interesante es la relacionada con la división o, mejor dicho, la relación entre los distintos poderes. Así, podemos encontrar como tipos ideales los modelos parlamentario y presidencialista ${ }^{20}$.

En buena medida la elección de un sistema político u otro viene determinada por el temor a un excesivo peso de uno de los tres poderes y no tanto por la preferencia por un sistema determinado. En los Estados Unidos, que son quizás el paradigma del presidencialismo, la configuración del sis-

19 Sobre las Constituciones y los Sistemas Políticos de la UE ver RIPOLLÉS, R. (coord.) Constituciones de los Estados Miembros de la Unión Europea, ed. Congreso de los Diputados, Madrid, 2011.

20 Algunos autores como Neustadt apunta que más que dividir en los sistemas políticos se debería hablar de compartir el poder. Ver NEUSTADT, R. E., Presidential Power and Modern Presidents: the Politics of Leadership from Roosevelt to Reagan, ed. Free Press, New York and London, 1991. 
tema político vino determinada por la relación de los colonos con el Parlamento Británico. Algunos de los padres fundadores, muy influidos por su experiencia negativa con Westminster, tenían una percepción extremadamente negativa del poder legislativo. El propio Alexander Hamilton consideraba que cuanto mayor fuera el número de personas que compusieran una cámara de representantes, más primaría la pasión sobre la razón, convirtiéndose así dicha asamblea en algo incontrolable ${ }^{21}$. Por ello, el temor de los colonos norteamericanos a un «legislativo tiránico» propició que el sistema político norteamericano se orientara hacia un modelo, inexistente hasta aquel momento, que dotaba de gran poder al ejecutivo. Esta elección no debía conllevar que el ejecutivo pudiera convertirse en la tiranía de un solo hombre y, para evitarlo, el sistema creó un legislativo y un judicial con grandes competencias. Incluso, estos otros poderes tendrían verdadera capacidad de bloqueo del poder ejecutivo. Al respecto, debemos mencionar que el órgano judicial encargado del control constitucional, el Tribunal Supremo, está presidido por un magistrado de designación presidencial, lo que refuerza aún más nuestro argumento del temor norteamericano al poder legislativo y de la búsqueda de un ejecutivo fuerte ${ }^{22}$.

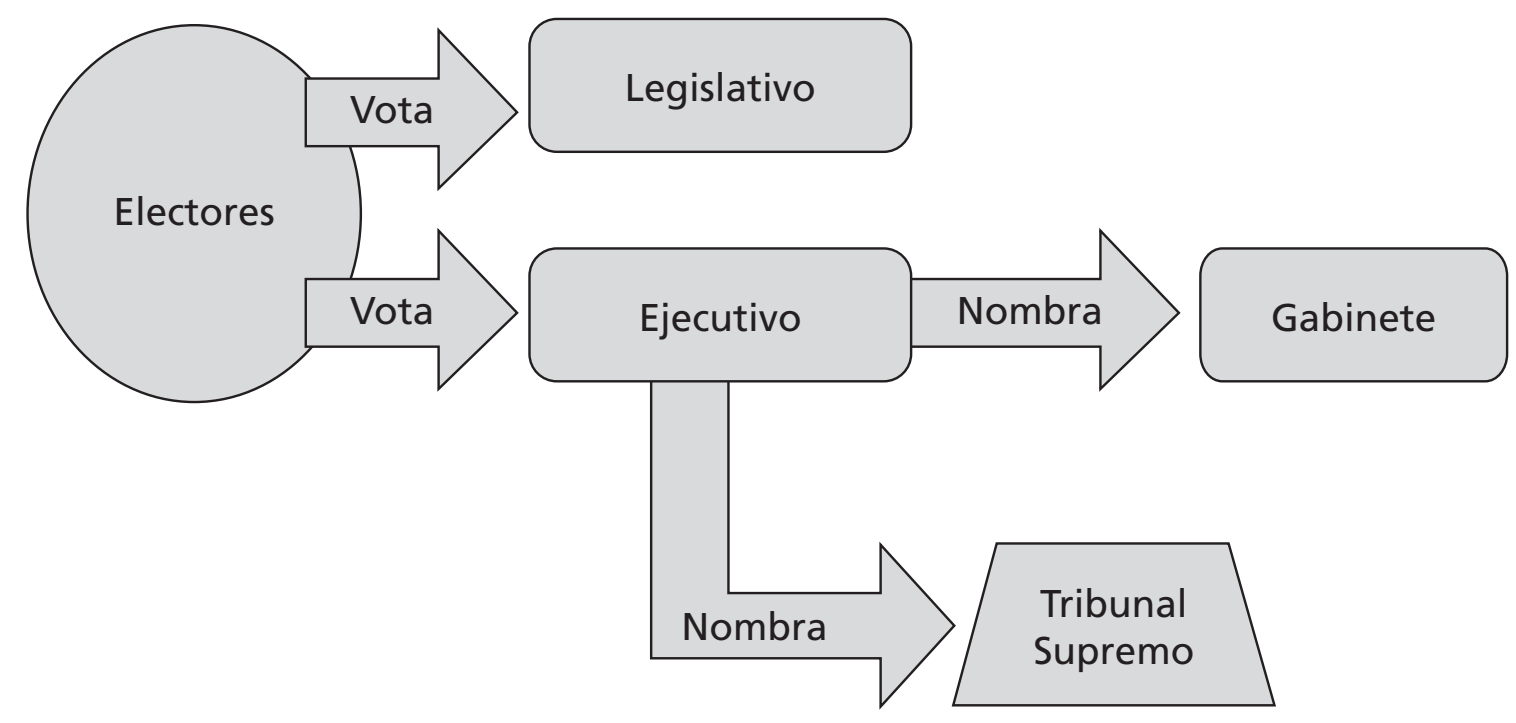

Fuente: Elaboración propia.

\section{Gráfico 2}

El Modelo Presidencial

21 «It is maintained that the authority of the Parliament is transcendent and uncontrollable» HAMILTON, A., «The Federalist Papers» An Electronic Classic Series Publication, ed. Pennsylvania State University, p. 240.

22 LIJPHART, A «The Westminster Model of Democracy» en MAYER, L., and PATTERSON, F., Contending Perspectives in Comparative Politics, C.Q. ed. Express-SAGE, Washington DC, 2009, p. 63. 
Tras la independencia de los Estados Unidos el resto de estados del continente americano fueron adoptando modelos presidencialistas similares al de Washington. Hoy América es un continente plenamente presidencialista con pequeñas diferencias en cuanto a la elección del presidente o a la limitación de mandato.

El caso de Europa responde a una lógica completamente distinta. Si bien es cierto que existió una importante relación entre los revolucionarios norteamericanos y los franceses, estos últimos siempre fueron muy cautelosos con la figura del Rey, figura que, por cierto, hasta la revolución estuvo ligada al poder ejecutivo. Estos temores, unidos a otros factores como una tradición dictatorial-cesarista, provocaron que las formas de gobierno parlamentarias fueran, y aún sean, las más populares en el continente europeo.

En el sistema parlamentario clásico el legislativo posee un papel muy destacado, siendo éste superior tanto al del ejecutivo como al del judicial. En los orígenes revolucionarios del sistema europeo, algunos autores como Sieyès propusieron incluso la creación de un órgano de control constitucional compuesto exclusivamente por parlamentarios. De este modo el poder judicial nunca podría ir en contra de la voluntad popular o seguir los dictados del ejecutivo. Este rasgo ha pervivido en cierto modo en el sistema británico donde - aunque solo con carácter notablemente excepcional- la Cámara de los Lores actuaba como instancia de apelación ante la que se podían recurrir las decisiones previamente ratificadas por la Corte de Apelación. En concreto, eran parte de los miembros de la Cámara de los Lores, los llamados «Lores de la Ley», los encargados de esta función, lo que evitaba la contradicción con el principio de división de poderes puesto que los lores encargados de ella no participaban en las sesiones celebradas por la cámara como institución legislativa (la menos relevante, en cualquier caso, de las dos que componen el Parlamento británico ${ }^{23}$.

Y es que, no en vano, siguiendo a Arend Lijphart una de las características del modelo Westminster, el más puro de los parlamentarios, es la concentración del poder del legislativo en una cámara, generalmente la cámara baja. Esta relevancia de las cámaras bajas permite que exista una cámara verdaderamente poderosa que controle al ejecutivo. El Parlamento Europeo seguiría esta misma línea ya que además de ser unicameral, posee algunas prebendas incluso superiores a las de los legislativos ${ }^{24}$ nacionales.

23 AJANI, G., ANDERSON, M., ARROYO-AMAYUELAS, E., and PASA, B., Sistemas jurídicos comparados. Ed. Universitat de Barcelona, Barcelona, 2010, p. 102.

24 «The EP's role is thus more proactive than that of most national parliaments in Europe» BOMBERG, E., PETERSON, J., and CORBETT, R., The European Union. How does it work? ed. Oxford University Press, Oxford, 2012, p. 149. 
Quizás el rasgo más significativo del sistema parlamentario sea que el legislativo es el encargado de elegir al que será el Jefe del Gobierno, procedimiento hay que unir que, en algunos casos como las repúblicas parlamentarias, el de que el legislativo se encargue de la elección del Jefe del Gobierno y del Jefe del Estado, lo que dota de aun más poder al legislativo. En lo que concierne a la elección del Jefe del Gobierno, la investidura puede correr a cargo de una de las cámaras o de las dos si hablamos de un sistema bicameral, aunque este segundo caso es mucho menos frecuente ${ }^{25}$. Pero, en todo caso, el futuro Jefe de Gobierno necesitará del consentimiento del legislativo para poder llevar a cabo su función como jefe del ejecutivo. Es esta concepción asimétrica del poder legislativo respecto de los otros dos poderes la que ha llevado a autores como Federico de Montalvo ${ }^{26}$ a hablar de legicentrismo. Aunque este tema será abordado en el siguiente apartado, ya vemos aquí un elemento que ha recogido el sistema político de la Unión Europea, la elección por parte del Parlamento Europeo del que puede ser considerado como Jefe del Gobierno - Presidente de la Comisión-.

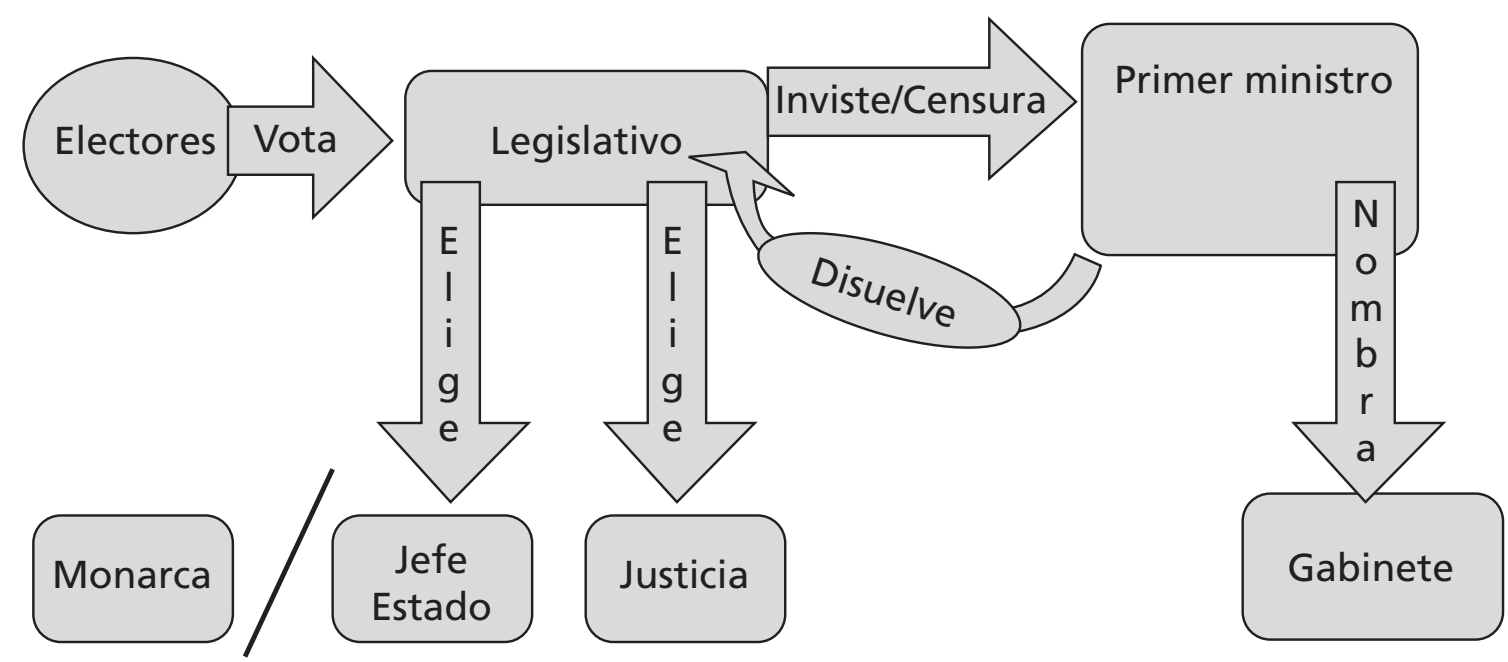

Fuente: Elaboración propia.

\section{Gráfico 3}

Modelo Parlamentario ${ }^{27}$

25 En Italia las dos cámaras intervienen en el proceso de elección del Primer Ministro.

${ }_{26}$ MONTALVO, F. y CORREAS, I., «Cincuenta años de presidencialismo en Europa: la evolución del semipresidencialismo» de la V República» Revista ICADE, No 83-84, 201, p. 381

27 «Most liberal democracies have adopted some form of parliamentary government» HEYWOOD, A., Politics, ed. Palgrave, London, 2013, p. 327. 
Tal y como hemos avanzado anteriormente, la preferencia por un sistema político u otro viene determinada más por elementos históricos y culturales que por una decisión vinculada con gobernabilidad ${ }^{28} \mathrm{o}$ con la legitimidad de los mismos. De hecho, tanto el sistema parlamentario como el presidencial presentan elementos positivos y negativos a la hora de valorarlos como sistemas políticos óptimos. Si bien es cierto que la separación de poderes es mucho más acusada en los sistemas presidenciales, no es menos cierto que el riesgo de bloqueo ${ }^{29}$ institucional es también mucho mayor. En todo caso, el modelo parlamentario presenta un aspecto fundamental para la supervivencia del propio sistema político: la inestabilidad política del gobierno no se convierte en inestabilidad del sistema ya que la capacidad de censura del parlamento sobre el primer ministro así como la capacidad de éste para disolver las cámaras, actúan como válvulas de escape para evitar el bloqueo institucional.

Con todo, en los casos de sistemas parlamentarios que cuentan con un sistema electoral excesivamente proporcional, como Bélgica, existe un riesgo mucho mayor: el de no poder formar gobierno. La solución a este problema puede ser doble. Por un lado, se pueden volver a convocar elecciones, aunque a veces los resultados no varían en exceso. Por otro, existe una solución que es otro rasgo característico de los sistemas parlamentarios: las coaliciones ${ }^{30}$. Los gobiernos de coalición o con apoyos puntuales, si bien es cierto que evitan el colapso del sistema, también complican a los ciudadanos la labor de atribuir responsabilidades a los integrantes del gobierno.

En todo caso, en aras de la gobernabilidad, la ingeniería constitucional ha aprendido que a veces los sistemas parlamentarios necesitan de algunos mecanismos presidenciales. Por ello, sin cambiar su esencia, los sistemas parlamentarios han ido acometiendo reformas que han «presidencializado» el modelo. De este modo, como forma de garantizar la gobernabilidad, progresivamente hemos asistido a una serie de correcciones del sistema que han concedido más poder al Jefe de Gobierno. Esta tendencia nos ha planteado una controversia doctrinal: la existencia de un tercer modelo que Du-

${ }^{28}$ Entendemos gobernabilidad con arreglo al uso del término que hace Pasquino, esto es, la capacidad de combinar estabilidad política y eficacia decisional. Ver capítulo 1 de PASQUINO, G., Sistemas políticos comparados: Francia, Alemania, Gran Bretaña, Italia y Estados Unidos. ed. Prometeo Libros, Buenos Aires, 2004.

${ }^{29}$ LINZ, J.J. y VALENZUELA, A., Las Crisis del presidencialismo, ed. Alianza, Madrid, 2011.

30 En Europa Occidental entre 1945 y 1999 tan sólo un 13\% de los gobiernos estuvieron compuestos por un solo partido con mayoría absoluta. Ver STROM, K. and NYBLADE, B., «Coalition Theory and Government Formation» en BOIX, C and STOKES, S., The Oxford Handbook of Comparative Politics, ed. Oxford University Press, Oxford, 2009, p. 792. 
verger denomina semipresidencial ${ }^{31}$ o de presidencialización del parlamentario.

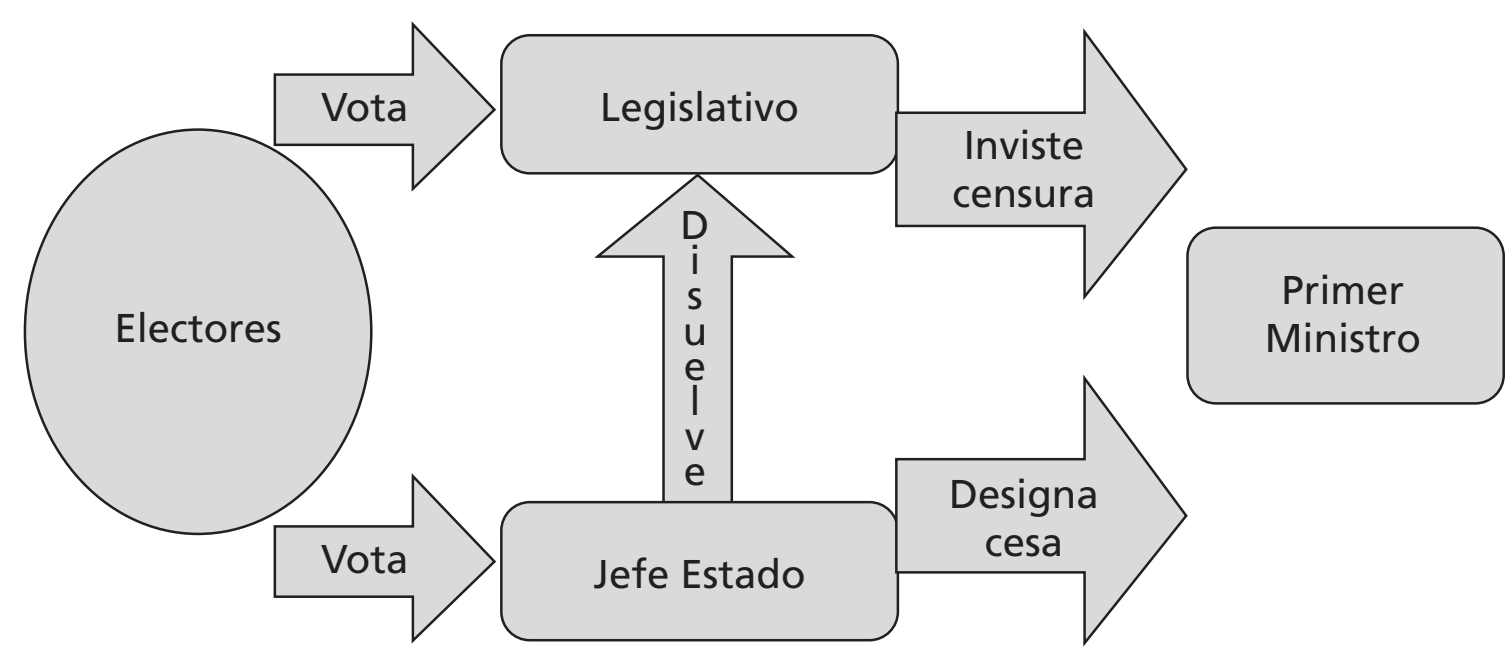

Fuente: Elaboración propia.

\section{Gráfico 4}

Modelo Semi-Presidencial

Autores como Bon, Sartori o Linz ${ }^{32}$ cuestionan la valía del término acuñado por Duverger y apuntan a un semi-parlamentarismo como respuesta a este fenómeno. En todo caso, el modelo semi-presidencial o semi-parlamentario debe enmarcarse en una tendencia, que nace en la Constitución de Weimar y que concluye con la democratización de los PECOS (Países de Europa Central y Oriental), y que tiene por objetivo el fortalecimiento de la figura del Presidente del Gobierno con el fin de garantizar la gobernabilidad. En esta línea encontramos trabajos que recogen esta dinámica políticoconstitucional calificándola como parlamentarismo racionalizado (España y Alemania $\left.{ }^{33}\right)$ o parlamentarismo negativo ${ }^{34}\left(\right.$ Suecia $\left.^{35}\right)$. Sin lugar a dudas el máximo exponente de esta forma de evolución lo encontremos en el sistema político francés, que en buena medida inspira a los antiguos miembros del bloque comunista. Por ello, podemos afirmar que en Europa encontramos

31 Ver DUVERGER, M., Les régimen semi-présidentiels, ed. PUF, Paris, 1996.

32 MONTALVO, F., y CORREAS, I., op. cit., nota 25, p. 382.

33 Sobre el modelo alemán ver DARANAS, M., «Alemania» en RIPOLLÉS, R. (coord.), Constituciones de los Estados Miembros de la Unión Europea, Congreso de los Diputados, Madrid, 2011.

34 MONTALVO, F., y CORREAS, I., op. cit., nota 25, p. 383.

35 Sobre el sistema político sueco ver ÁLVAREZ, M., «Suecia» en RIPOLLÉS, R., op. cit., nota 19. 
una ola de presidencialización de los regímenes parlamentarios que afectaría con distinta intensidad a casi todos Estados. Así, el sistema político menos afectado sería el británico donde, por ejemplo, el Premier necesita del Parlamento para casi cualquier medida, y el más afectado sería el francés donde el Jefe del Estado actúa, en cierta medida y para ciertos temas, como el Presidente de los Estados Unidos.

Este elemento de presidencialización, o más exactamente en este caso, de combinación de aspectos propios del sistema parlamentario con elementos característicos del sistema presidencialista es, por otra parte y como se ha indicado, uno de los rasgos observables en el sistema político de la Unión Europea.

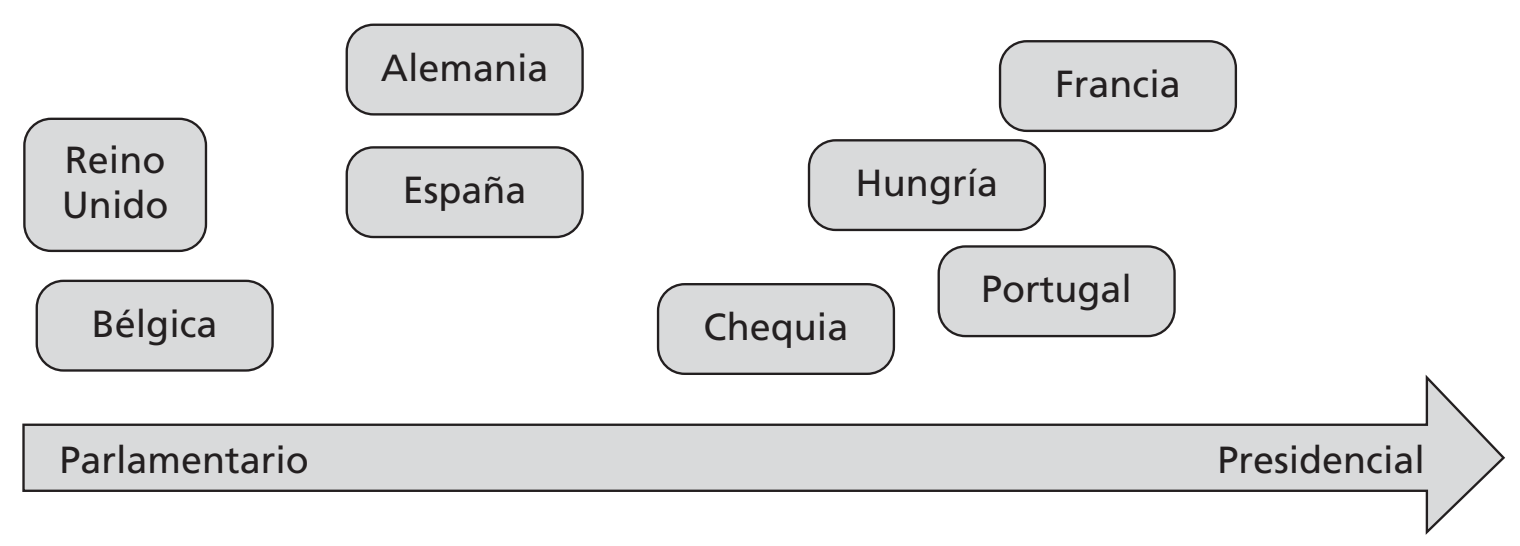

Fuente: Elaboración propia.

\section{Gráfico 5}

Semipresidencialización de los sistemas políticos en Europa

Realizada la revisión de los modelos políticos existentes tanto en América como en Europa, así como de las principales tendencias que han provocado las reformas de los mismos, cabe preguntarse cuál es el modelo que está adoptando la UE y que opción puede otorgarle más legitimidad ante sus ciudadanos. Conviene no olvidar la premisa fundamental de la que partíamos: la UE se encuentra «limitada» por una estructura institucional cuya reforma es casi imposible por la existencia de dos modelos o proyectos casi irreconciliables y la inclusión de elementos propios de los sistemas políticos clásicos es prácticamente la única vía posible (aunque no sencilla) para tal reforma. 


\section{La Unión Europea como sistema político}

Sobre la base del análisis de la estructura inicial de la Unión, las distintas sensibilidades en la integración y los sistemas políticos clásicos planteado más arriba, vamos a intentar esclarecer cómo se distribuye el poder dentro de la UE poniéndolo en relación con la división de poderes clásica. Así, siguiendo este criterio el poder legislativo, ejecutivo y judicial de la UE quedarían configurados de la siguiente manera:
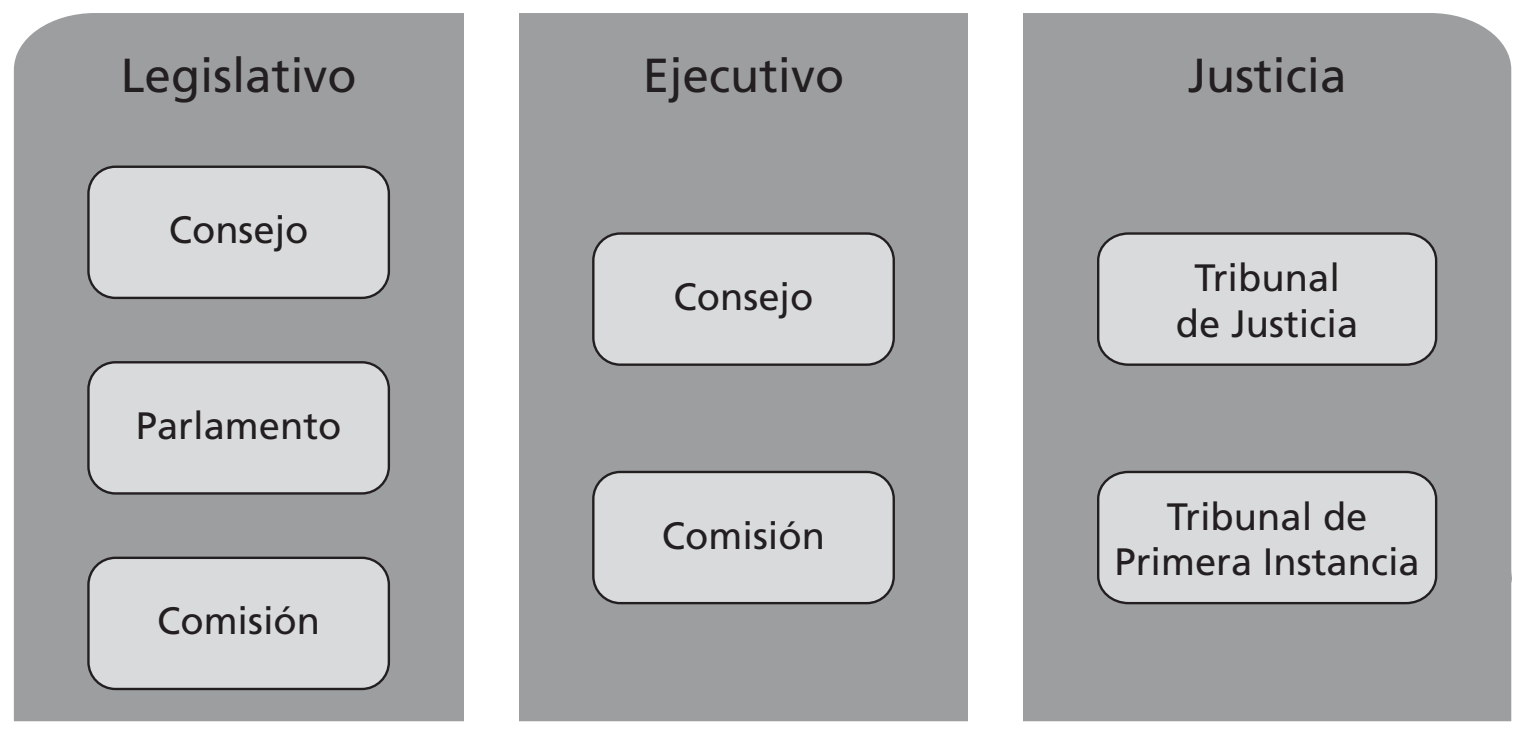

Fuente: Elaboración propia.

\section{Gráfico 6}

Distribución (clásica) de poderes en la UE

Veamos cuáles han sido las principales características adoptadas desde los sistemas parlamentarios. Si nos fijamos en la configuración inicial del poder en la Unión Europea (Gráfico 1) y en la actual vemos que a lo largo de estos 60 años se han ido incorporando elementos propios del sistema presidencial y, sobre todo, del sistema parlamentario, aunque respetando la estructura inicial de la CECA. Esta evolución es lo que Jo Shaw ha denominado «polity-in-the-making ${ }^{36} »$.

La Unión Europea ha ido ampliando progresivamente el rol del Parlamento Europeo, incrementando con ello, al propio tiempo, su legitimidad democrática. En esta línea, desde el Tratado de Ámsterdam, la Unión Euro-

36 NEUNREITHER, K., and WIENER, A. (eds), European Integration after Amsterdam, ed. University Press, Oxford, 2000, p. 291. 
pea ha incorporado el proceso de investidura - propio de los sistemas parlamentarios - como procedimiento para la elección del Presidente de la Comisión (arts. 14.1 y 17.7 TUE)

En este sentido, si en los sistemas parlamentarios clásicos es el Jefe del Estado (Rey o Presidente de la República) quien propone al futuro jefe del ejecutivo, en la Unión Europea el encargado de proponer al futuro Presidente de la Comisión es el Consejo. Una vez el Presidente de la Comisión haya sido elegido, éste, contando con el propio Consejo, elaborará un proyecto de lo que será su equipo de gobierno (arts. 17.3, 17.5 y 17.7 del TUE). Éste último matiz es un elemento propio del sistema político de la unión ya que la dualidad del ejecutivo (Consejo-Comisión) provoca que el Presidente de la Comisión no tenga libertad plena para elegir a su equipo al tiempo que empuja al proyecto europeo en una línea más cercana a los deseos de los funcionalistas o, dicho de otro modo, de quienes prefieren que los estados retengan el papel de mayor relevancia en el proceso.

Por otra parte, la Unión Europea se ha caracterizado por el fomento de acuerdos entre las principales fuerzas políticas. De hecho, hasta la fecha se ha respetado que la Presidencia del Parlamento Europeo sea «compartida» entre el Partido Popular Europeo y los Socialdemócratas europeos. Sin embargo, debido a la cada vez más patente fragmentación del arco parlamentario europeo, provocada en cierta medida por la ausencia de un procedimiento electoral unificado, que no obstante si recogen los tratados que debería establecerse, cada vez más se hacen necesarias las coaliciones para garantizar la gobernabilidad (art. 14.4 TUE). Estas coaliciones o pactos de legislatura, más visibles tras las últimas elecciones, que suelen comenzar con un acuerdo por la presidencia de la cámara y continuar con la elección del Jefe del Gobierno y de los miembros del gabinete son, como veíamos más arriba un rasgo característico de numerosos sistemas parlamentarios.

Mención aparte merece la moción censura, elemento exclusivo de los sistemas parlamentarios ya que por la división de poderes no se plantea en los sistemas presidenciales, donde el legislativo no nombra al ejecutivo y, por la misma razón, tampoco puede cesarlo. En un intento de ir incrementando la democratización del sistema político, la UE ha asumido este rasgo de los sistemas parlamentarios (art. 17.8 TUE). El legislativo europeo - el Parlamento, en concreto- al igual que otros poderes legislativos como el alemán, el italiano y o el español tiene capacidad para censurar al ejecutivo si considera que éste no está ejerciendo sus competencias de acuerdo a las normas de la unión (art. 234 TFUE). Aunque el requisito de la mayoría cualificada (2/3) implica la necesidad de un gran consenso para acabar con el ejecutivo, la posibilidad de censura supone en sí misma un poder muy con- 
siderable para el legislativo. En realidad, ya se ha recurrido a este mecanismo pues en 2004 el Parlamento Europeo planteó una moción de censura contra la Comisión que entonces lideraba el italiano Romano Prodi.

En otro orden de cosas hay que mencionar que entre las funciones clásicas de los poderes legislativos está la función presupuestaria función que, de acuerdo con la modificación del TUE acometida en (art. 314 TFUE) asume aún en mayor medida que antes el Parlamento Europeo. El fin no es otro que atribuir mayores poderes al legislativo, lo que confirma una vez más nuestra hipótesis acerca de la parlamentarización del sistema político de la UE y su relación con la democratización del mismo. No obstante, al igual que ocurre con la función legislativa, hay que decir que la presupuestaria es una función compartida con el Consejo y la Comisión.

Por último cabe mencionar la elección del Presidente del Consejo Europeo (art. 15.6 TUE) como una figura moderadora del sistema que bien puede equipararse con otras figuras como los Presidentes de Italia, Alemania o Israel. Si bien alguien pudo pensar que se trataba de un Jefe de Estado fuerte al estilo del Presidente de los Estados Unidos, la ausencia de competencias aclara cualquier duda y ratifica la voluntad de parlamentarizar el sistema político de la Unión Europea. Sin embargo, hay que mencionar un aspecto de la propia elección del Presidente del Consejo que no está en línea con los ejemplos que hemos señalado anteriormente. Si en el caso de Italia, Alemania o Israel el Jefe de Estado es elegido por el parlamento, aquí lo elige el Consejo (art. 15.5 TUE) (aunque es cierto que, en el particular sistema de la UE el poder legislativo lo comparten el Parlamento y la Comisión).

\section{Conclusiones}

Hemos visto cómo, sin poner en cuestión la rígida estructura institucional establecida en 1952 en la CECA, pero tratando de reformarla, la Unión Europea ha ido incorporando elementos propios de los sistemas políticos clásicos, especialmente el sistema parlamentario, atribuyendo con ello progresivamente más poder al Parlamento Europeo. En consecuencia, resulta razonable afirmar que el sistema político de la UE se encuentra inmerso en un proceso de parlamentarización.

Tal proceso resulta doblemente interesante si tenemos en cuenta que quizás la principal crítica que se vierte contra la Unión Europea sea la escasa participación de los ciudadanos en el sistema político. En efecto, de acuerdo con Priban, de las tres características que Lincoln atribuía a toda 
democracia (del pueblo, por el pueblo y para el pueblo) el sistema político de la UE solo cumple con la última ${ }^{37}$.

Pues bien, la parlamentarización implica reforzar progresivamente los poderes, las competencias de la institución que representa a los ciudadanos, el Parlamento Europeo. Dicho proceso comenzó con la firma del Tratado de Ámsterdam, cuando se introdujeron medidas como la investidura del Presidente de la Comisión o los procedimientos legislativos de codecisión. Desde entonces y sin alterar la estructura institucional el sistema político de la Unión Europea, éste tiende a parecerse cada vez más a los sistemas parlamentarios que, dicho sea de paso, son los más comunes en Europa, especialmente en Europa Occidental. Si bien es cierto que la Unión Europea no puede escapar de la tendencia que sufren los sistemas parlamentarios Europeos, la presidencialización, el poder legislativo tiene cada vez más poder en las decisiones de la Unión Europea.

Incluso, se podría hablar de una tendencia al modelo de Westminster ya que el sistema europeo posee algunas de las características, aunque no todas, señaladas por Lijphart como propias de este sistema. Si bien es cierto que no se puede hablar de gobiernos de un solo partido, sí que podemos identificar otros elementos como la existencia de un gobierno que depende de la confianza del legislativo, cierta flexibilidad constitucional o la concentración de los poderes del legislativo en una sola cámara ${ }^{38}$.

Además de estas características existen otras que nos muestran el acercamiento de la UE al modelo parlamentario. Por ejemplo, debido a la creciente heterogeneidad de la sociedad europea se ha incrementado la tendencia multipartidista del Parlamento Europeo. Dada la situación de pluralismo social y político existente, las coaliciones se hacen casi imprescindibles para garantizar la gobernabilidad del sistema tal y como ha demostrado el proceso de composición de la Comisión Junker.

Todos esos cambios, al conducir a la parlamentarización y, con ello, a una mayor participación de los ciudadanos, contribuyen a reducir el déficit democrático de la UE y, junto a él, su falta de legitimidad.

37 «The absence of two out of Lincoln's three characteristics of democratic government, namely, government 'of the people' and 'by the people', makes the EU's political system one which primarily operates 'for the people' or, better, 'for the peoples of the EU» PRIBAN, D., «The Self-Referential European Polity, its Legal Context and Systemic Differentiation: Theoretical Reflections on the Emergence of the EU's Political and Legal Autopoiesis» European Law Journal, Vol. 15, No. 4, July 2009, p. 443.

38 Ver LIPHART, A., op. cit., nota 22. 


\section{Bibliografía}

ABAD, G., «Mayo 2014: Las elecciones del desencanto» The Economy Journal, Mayo 2014, pp. 21-24.

AHIJADO, M., Historia de la unidad europea. Desde los precedentes remotos a la ampliación al Este, Ediciones Pirámide, Madrid, 2000.

AJANI, G., ANDERSON, M., ARROYO-AMAYUELAS, E. and PASA., Sistema jurídicos comparados. Ed. Universitat de Barcelona, Barcelona, 2010, p. 102.

ÁLVAREZ, M. I., «Constitución de Francia» Revistas de la Cortes Generales,

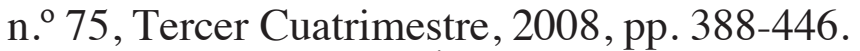

ÁLVAREZ, M. I., y ALCÓN, F., «El Parlamento Europeo. Notas sobre la Representación Política y los Sistemas Electorales» Revista de Derecho Político, n. ${ }^{\circ}$ 52, 2001, pp. 323-354.

BOMBERG, E., PETERSON, J., and CORBETT, R., The European Union. How does it work?, Oxford University Press, Oxford, 2012.

BOIX, C and STOKES, S., The Oxford Handbook of Comparative Politics, Oxford University Press, Oxford, 2009.

BUTKOVIC, «How is Democracy Applied within the EU:Combining Elements of Traditional and Innovative Democratic Practice», Politička misao, Vol. 47, No. 5, 2010, pp. 27-43.

CAPORASO, J.,«The European Union and Forms of State: Westphalian, Regulatory or Post-Modern?» Journal of Common Market Studies, Volume 34, Issue 1, 1996, pp. 22-55.

CLOSA, C., Sistema Político de la Unión Europea, Editorial Complutense, Madrid, 1997.

DUVERGER, M., Les régimen semi-présidentiels, PUF, Paris, 1996.

FORNER, S. (ed.) La construcción de Europa. De las guerras civiles a la unificación. Biblioteca Nueva. Insituto Alicantino de Cultura Juan Gil-Albert, Madrid, 2007.

GRAJAUSKAS, R., and KASCIUNAS, L., «Modern versus Postmodern Actor of International Relations: Explaining EU-Russia Negotiations on the New Partnership Agreement», Lithuanian Foreign Policy Review, 2009 (22).

HAGUE, R., \& HARROP, M., Comparative Government and Politics. An Introduction. Palgrave, London, 2011.

HAMILTON, A., The Federalist Papers, An Electronic Classic Series Publication, Pennsylvania State University, 1998.

LINZ, J.J. y VALENZUELA, A., Las Crisis del presidencialismo Alianza, Madrid, 2011.

MAYER, L., and PATTERSON, F., Contending Perspectives in Comparative Politics, C.Q. Express-SAGE, Washington DC, 2009.

McSWEENEY, B., Moral Issues in International Affairs, MacMillan, New York/ Cambridge, 1998.

MONTALVO, Federico y CORREAS, Irene «Cincuenta años de presidencialismo en Europa: la evolución del semipresidencialismo» de la V República» Revista ICADE, n. ${ }^{\circ} 83-84$, Especial 50 aniversario, 2011, pp. 379-402. 
MORAVCSIK, A., «New Statecraft? Supranational Entrepreneurs and International Cooperation» International Organization, vol 53, n. ${ }^{\circ}$ 2, Spring 1999, pp. 267306.

NEUNREITHER, K., and WIENER, A. (eds), European Integration after Amsterdam, Oxford University Press, Oxford, 2000.

NEUSTADT, R. E., Presidential Power and Modern Presidents: the Politics of Leadership from Roosevelt to Reagan, Free Press, New York and London, 1991.

NUGENTS, N., The Government and Politics of the European Union, Palgrave, MacMillan, 2010 (7th edition).

PASQUINO, G., Sistemas políticos comparados: Francia, Alemania, Gran Bretaña, Italia y Estados Unidos. Prometeo Libros, Buenos Aires, 2004.

PETERSON, J., and SHACKLETON, M., The Institutions of the European Union, Ed Oxford University Press, Oxford, 2012.

PINELLI, C., «The Discourses on Post-National Governance and the Democratic Deficit Absent an EU Government» European Constitutional Law Review, September 2013, pp. 177-188.

PRIBAN, D., «The Self-Referential European Polity, its Legal Context and Systemic Differentiation: Theoretical Reflections on the Emergence of the EU's Political and Legal Autopoiesis» European Law Journal, Vol. 15, No. 4, July 2009, pp. 442-461.

RIPOLLÉS, R. (coord.) Constituciones de los Estados Miembros de la Unión Europea, Congreso de los Diputados, Madrid, 2011.

RITTBERGER, R., «Which institutions for post-war Europe? Explaining the institutional design of Europe's first community» Journal of European Public Policy Vol. 8 Issue 5, October 2001, pp. 673-708.

SCHARPF, F.W., «The Joint-Decision Trap: Lessons from German Federalism and European Integration», Public Administration, No. 66, 1988, pp. 239-278.

SCOTTO, M., Las Instituciones Europeas, Le Monde-Salvat, Madrid, 1996.

STAAB, A., The European Union Explained, Indiana University Press, Bloomingon, 2012.

VILARIÑO, E., La construcción de la Unión Europea, Arco Libros, Madrid, 1996. 